\title{
Stimmen von einst. Jiddisch in der Literatur Polens
}

Die Welt am anderen Ende / vergeß ich nie. / Wohin ich geh, mich auch wende, / suche ich sie. (STANISŁAW JERZY LEC) ${ }^{1}$

Wychodząc z założenia, że nowoczesna literatura w jidysz, której kolebką jest polska ziemia, jest częścią literatury polskiej (Marian Fuks), rozważa się stosunek czworga poetów piszących po polsku lub w jidysz -Juliana Tuwima, Rajzli Żychlińskiej, Abrahama Sutzkevera i Arnolda Słuckiego - do literatury i kultury w obydwóch językach. Ich znaczenie jako pośredników między tymi dwoma biegunami polskiej kultury było tylko tymczasowe. W dzisiejszej Polsce jedynie Tuwim i Słucki są uważani za polskich poetów, natomiast poeci piszący w jidysz są nieznani lub zapomniani.

Ausgehend von dem Postulat, dass die moderne jiddische Literatur, die auf polnischem Boden entstand, Teil der polnischen Literatur ist (Marian Fuks), wird das Verhältnis von vier Dichtern polnischer und jiddischer Sprache - Julian Tuwim, Rajzel Żychlińska, Abraham Sutzkever und Arnold Słucki - zur polnisch- und jiddischsprachigen Literatur und Kultur beleuchtet. Ihre Funktion als Bindeglied und Mittler zwischen den beiden Polen der Literatur Polens war jedoch nicht von Dauer. Während heute in Polen nur noch Tuwim und Słucki als polnische Dichter wahrgenommen werden, sind die jiddisch schreibenden Dichter unbekannt oder vergessen.

Regarding the thesis that modern Yiddish literature which came into being on Polish soil is a part of Polish literature (Marian Fuks), the attitude of the four poets who wrote in Polish or in Yiddish - Julian Tuwim, Rajzel Żychlińska, Abraham Sutzkever and Arnold Słucki - towards literature and culture in Polish and Yiddish are scrutinized. Their function as bridges between the two poles of Polish culture was only temporary. While only Tuwim and Słucki are regarded as Polish writers in Poland today, the other two poets, who wrote in Yiddish, are unknown or forgotten.

1 Gedicht Heimweh von STANISŁAW JeRZY LEC (1986:85). 
Die hier im Weiteren als polnische Dichter (und Dichterinnen) bezeichneten Autoren waren zwar ihrer Herkunft nach Juden, doch sie fühlten sich mehrheitlich als Polen, liebten ihr Heimatland, das sie verlassen mussten, seine Kultur und Literatur, auch dann, wenn sie die traditionelle Sprache der polnischen Juden, das Jiddische, neben dem Polnischen sprachen, in dieser Sprache schrieben und ihre Kultur lebten. Wenn auch manches dagegen sprechen mag, muss man diese Dichter, zu denen unter anderen Rajzel Żychlińska und Abraham Sutzkever gehören, dennoch genauso wie Julian Tuwim und Arnold Słucki als polnische Dichter bezeichnen, denn die jüdische Literatur Polens auch in Hebräisch und Jiddisch wird inzwischen von einigen Forschern als integraler Teil der Literatur Polens betrachtet, wiewohl sich diese Erkenntnis noch nicht überall durchgesetzt hat. ${ }^{2}$

Ähnlich dem Patriotismus deutscher Juden und ihrer unerwiderten Liebe zu Deutschland und der deutschen Kultur, die leichtfertig als „deutsch-jüdische Symbiose" bezeichnet wird, bestand eine ,Liebesbeziehung " zwischen den polnischen Juden und ihrer Heimat Polen. Diese Beziehung war nicht einfach, vielfach konfliktreich, meist einseitig, sie erlebten nach dem Krieg eine Enttäuschung, die sie - außer im Falle Julian Tuwims, der 1946 aus New York nach Polen zurückkehrte - endgültig in die Emigration trieb. Doch auch Tuwim erlebte im stalinistisch gewordenen Polen eine existentielle und Schaffenskrise.

Die Akkulturation der polnischen Juden setzte im Vergleich zu jenen im Deutschen Reich relativ spät ein. Als im letzten Viertel des 19. Jhd.s das unter drei fremden Mächten aufgeteilte Polen de jure als Staat nicht mehr existierte und seine Kultur und Sprache unterdrückt wurden, begannen die Juden Polens, die bis dahin Polnisch in der Regel kaum oder wenig beherrschten, sich langsam in der polnischen Gesellschaft zu assimilieren. ${ }^{3}$ Das führte dazu, dass in den 1880er Jahren die ersten vereinzelten Übersetzungen aus dem Jiddischen ins Polnische publiziert wurden. Am Anfang des 20. Jhd.s verstärkte sich dieses Phänomen, insbesondere nachdem Polen 1918 als

2 Einen maßgeblichen Anteil an dieser Erkenntnis hat EugENIA ProKOP-JANIEC mit ihren ergiebigen Studien, deren Kenntnis hier vorausgesetzt wird, wie (1992) oder (1996); ebenfalls MARIAN FuKS (2002); auch MARIAN STĘPIEŃ (1989). Interessanterweise wurde früher wie bei WŁODZIMIERZ MACIĄG (1981) die jüdische Herkunft der Schriftsteller wie Tuwim, Słucki, Winawer u.a. konsequent verschwiegen.

3 So z.B. der aus Galizien stammende Literaturkritiker und Publizist Wilhelm Feldman (1868-1919). 
unabhängiger Staat wieder auferstanden war. Neben dem Patriotismus der polnischen Juden wuchs auch ihr Selbstbewusstsein, was mit einer breiteren Akzeptanz auch der jiddischsprachigen Literatur im europäischen Kontext einherging. Die nun assimilierten Juden - manche von ihnen, wie Roman Brandstaetter (1906-1987), traten zum Katholizismus über und nannten sich „Polen jüdischer Abstammung“ ${ }^{\text {“4 }}$ - hatten als Erben der Aufklärung jetzt das Bedürfnis, ihre eigene, lange verkannte jüdische Kultur der polnischen Intelligenz zu vermitteln. Die nunmehr entstandene polnischsprachige jüdische Presse wurde auch von Nichtjuden gelesen (vgl. FUKS 1979). So bahnte sich eine neue Ära in den polnisch-jüdischen Beziehungen an, doch der Antisemitismus war nach wie vor präsent, und der Zweite Weltkrieg beendete die kurze, knapp zwanzigjährige polnisch-jüdische kulturelle Blüte der Zwischenkriegszeit.

Ihre Pioniere und Protagonisten sind dem heutigen deutschen Leser - mit Ausnahme vielleicht von Julian Tuwim (1894-1953) und Bruno Schulz (1892-1942) - im Allgemeinen leider wenig bekannt. $\mathrm{Zu}$ denjenigen, die weniger geläufig sind, gehören Namen wie Antoni Lange (1861 oder 18631929), Bolesław Leśmian (1877-1937) ${ }^{5}$, Antoni Słonimski (1895-1976), Marian Hemar (1901-1972), Jan Brzechwa (1898-1966), Jan Lechoń (18991956), Tadeusz Peiper (1891-1969), Anatol Stern (1899-1968), Aleksander Wat (1900-1967), Artur Sandauer (1913-1989), aber auch die heute zu Unrecht fast vergessenen, von den Nationalsozialisten ermordeten Zuzanna Ginczanka (1917-1944) oder Maurycy Szymel (1903-1942), der sowohl in Jiddisch als auch in Polnisch publizierte. Ob traditionell jüdisch oder modern erzogen, wählten diese die polnische Sprache für ihr literarisches oder publizistisches Schaffen.

4 NAthan CoHEN (2003:165) weist darauf hin, dass sich auch Tuwim vor dem Krieg so bezeichnete, während er sich 1944 im Krieg „umbenannte“, wie in seinem Poem My, Żydzi Polscy [Wir, die polnischen Juden] zu lesen ist. Das war unter dem Eindruck der Nachrichten über die Ermordung der Juden durch die Nationalsozialisten geschehen, der Tuwims in Polen verbliebene Mutter zum Opfer fiel. Noch im Jahre 1982 veröffentlichte ARTUR SANDAUER ein Buch unter dem bezeichnenden Titel „Über die Lage eines polnischen Schriftstellers jüdischer Abstammung im 20. Jahrhundert".

5 Die Slawistin HerTa SCHMID (1998) geht den Besonderheiten der dichterischen Sprache von Schulz und Leśmian nach und zieht eine Verbindung zu deren jüdischen Ursprüngen. 


\section{Julian Tuwim}

Tuwim (vgl. GRÖZINGER 1983, 1989) gilt nun, unabhängig von seiner Selbstverortung als polnischer Jude, wie sie aus seinem im Krieg verfassten manifestartigen Poem „Wir, die polnischen Juden...“ (TUWIM 1984) hervorgeht, als ein schlechthin polnischer Dichter, als polnischer Nationaldichter par excellence, der nicht Jiddisch oder Hebräisch, sondern Polnisch schrieb, sich als Pole fühlte und dennoch dem jüdischen Schicksal nicht entrinnen konnte. Geboren in einer assimilierten und polonisierten jüdischen Familie in Lodz (die Stadt, die er liebte: ,... o, citta dolente, jakże się to stało, że cię tak wielką i serdeczną miłością pokochałem?" - TUWIM 1964:15) ${ }^{6}$, trug er wie sonst nur wenige zur Renaissance der polnischen Sprache und Literatur bei. Darüber, ob er Jiddisch verstand, gibt es Meinungsverschiedenheiten. Die einen behaupten, er hätte davon nicht die geringste Ahnung gehabt, die anderen billigen ihm hingegen zwar keine aktive jiddische Sprachkenntnis zu, meinen aber, dass er es durchaus verstanden hat, was eher wahrscheinlich ist, denn er wuchs in Lodz auf, einer Stadt mit großer Textilindustrie, in der Juden tonangebend waren und die zur Zeit seiner Geburt an die 100.000 jüdische Einwohner hatte, die mehrheitlich Jiddisch sprachen. Da Tuwim wie die meisten Lodzer neben Russisch auch Deutsch und Französisch konnte, ist es unwahrscheinlich, dass jemand mit seiner großen Sprachbegabung gerade am Jiddischen gescheitert wäre, zumal es in der Stadt auch eine rege Theateraktivität in Jiddisch gab und er ein vielbeschäftigter Bühnenautor war. Auch hatte er orthodoxe Verwandtschaft, ,mit Schläfenlocken“, die sicherlich Jiddisch sprach, und mit der er nach Aussagen von Zeitgenossen engen familiären Kontakt pflegte. ${ }^{7}$ Dass dieses Milieu ihm nicht fremd war, zeigt z. B. auch der Artikel über Podróże i geszefty stawnego rabina [Reisen und Geschäfte [sic! Jiddisch] des berühmten Rabbiners] aus der Gazeta Warszawska 8 (1874), den TUWIM (1963:126f.) in seine Sammlung Cicer cum Caule czyli Groch z kapusta [Cicer cum Caule oder Kraut mit Rüben] aufgenommen hatte. Vor dem Ausbruch des Zweiten Weltkriegs lebten in Lodz 233.000 Juden, etwa ein Drittel der Gesamtbevölkerung. Tuwim lebte damals zwar schon in Warschau, doch die engen Bande nach Lodz hielten

6 ,Oh, citta dolente, wie ist es geschehen, dass ich dich so sehr und von ganzem Herzen liebgewonnen habe?

7 Laut SAMUEL Scheps (1989:210), der den Dichter Stanisław Baliński (18981984) zitiert. Dieser gehörte zum Freundeskreis von Julian und Stefa Tuwim und traf diese Verwandten bei Feiern, wie er in Twórczość 5 (1983) schrieb. 
sogar noch über den Ozean hinweg, wohin er vor den Nazis floh. Die Liebe zu Polen war bei ihm stärker als die Angst vor einer Ablehnung seitens national gesinnter Juden, die ihn für einen „Renegaten“ hielten und denen er frech entgegenrief, was noch heute von Antisemiten gern zitiert wird: „Ihr könnt mich alle mal...". ${ }^{8}$ Stärker war Tuwims Liebe aber vor allem als seine Abscheu vor den zeitgenössischen Antisemiten. Dass der Judenhass in seinem geliebten Heimatland präsent, ja, oft gewalttätig war, und sich in Pogromen entlud, wusste er nur allzu gut. Bereits 1914 schrieb er, sich prophetisch als „Semit“ bezeichnend, Pieśń o biciu [Lied über das Schlagen] der Juden durch die ,Arier', in dem es hieß:

A gdy to bȩdziesz czytać, przyszły czytelniku,

To zȩby ściśnij, to ściśnij pięści:

- Za rozpacz mego zdławionego krzyku,

Za serce moje, szarpane na części!

Żydów biją! Wesoło! Ha-ha-ha!

Żydów biją! Bẹdą i mnie bili:

Batogiem w pysk,

Nahajką w plecy,

Żelastwem w głowę,

Wesoło!!!

[...]

Biją Polacy, Rosjanie,

Tak, tak: słoneczni Słowianie!

MNIE także bȩdą bić!

[...] (TUwIM 1990:121) ${ }^{9}$

8 Das satirische Gedicht von Tuwim Catujcie mnie wszyscy $w$ dupẹ aus der Zwischenkriegszeit (wohl aus Jarmark Rymów von 1934) ist im heutigen Polen sehr populär, sei es als Hip-Hop oder (im Januar 2011) als Lied im Rahmen einer Tuwim gewidmeten Revue mit dem Titel Tuwim dla dorostych [Tuwim für Erwachsene] im Warschauer Musik-Theater Roma. Das Gedicht nimmt seine Kritiker - Juden und Nichtjuden - sowie die Zensoren in einer groben Weise aufs Korn, wird aber in polnischen Internetforen auch im antisemitischen Kontext zitiert.

9 ,Und wenn du dies, künftiger Leser, lesen wirst / Dann presse die Zähne zusammen, und balle die Fäuste: / - Für die Verzweiflung in meinem erstickten Schrei, / Für mein Herz, in Stücke gerissen! // Sie schlagen die Juden! Lustig! Ha-ha-ha! / Sie schlagen die Juden! Und auch mich werden sie schlagen: / Mit der Peitsche in die Fresse, / Mit der Knute auf den Rücken, / Mit der Eisenstange auf den Kopf, / Lustig!!! [...] Es schlagen die Polen, die Russen, / Ja, ja: die sonnigen Slawen! / Auch MICH werden sie schlagen!' (Übersetzung E. G.) 
Die Antisemiten hatten ihn zwar nicht physisch geschlagen, doch ihn vermehrt in den 1930er Jahren angegriffen, wiewohl er bereits nach seinem lyrischen Debüt mit dem vitalistischen Dithyrambus Frühling im Jahre 1918 zur Zielscheibe von Attacken (,jüdischer Pornograph“) des Publizisten Adolf Nowaczyński (1876-1944) geworden war, der den polnischen Rechten nahestand, den Nationaldemokraten um Roman Dmowski. Seit 1934 wurde Tuwims jüdische Herkunft verstärkt das Thema von öffentlichen Attacken der rechtsgerichteten Presse wie in Myśl Narodowa [Nationales Denken], wo man ihm ,geraten' hatte, einen schwarzen Kaftan, wie ihn die Chassidim tragen, anzuziehen und ins Ghetto zurückzukehren und im ,Jargon', Jiddisch, zu schreiben. Tuwim antwortete scheinbar launig und unbekümmert darauf, dass derjenige, der das geschrieben habe, seine altpolnische Tracht anziehen möge, damit sich beide zusammen zum Ergötzen des Publikums fotografieren lassen könnten. Nebenbei wies er allerdings apologetisch eigens darauf hin, dass er nicht aus einem Ghetto komme und Jiddisch nicht beherrsche (GRÖZINGER 1999:160). Man muss den Kontext einer solchen Aussage vor Augen haben, um ihren Stellenwert richtig einzuschätzen, und sie keineswegs für bare Münze nehmen. Denn dies war ein Generalangriff auf seine Identität, auf alles, was Tuwim lieb und teuer war, weil die Antisemiten, wie etwa Karol Hubert Rostworowski (HERTZ 1988:191), ihm als Juden das Recht absprachen, auf Polnisch zu schreiben, oder wie ein Stanisław Maykowski, der meinte, dass ,wir Tuwim zwar wie einen begabten ausländischen Schriftsteller schätzen können. Als unseren, als bodenständigen Dichter werden wir ihn aber niemals betrachten." ${ }^{10}$ Es hieß über Tuwims Verse zudem, sie seien „semitisch durchtränkt“, würden „,talmudischen Geist“" atmen, was mit „unpolnisch“ oder ,entartet“ gleichgesetzt wurde. Tuwim, den diese Infamie zutiefst verletzte, erwiderte seinerseits mit bissigem Spott und Verachtung: „Próżnoś repliki się spodziewał / Nie dam ci prztyczka ani klapsa. / Nie powiem nawet pies cię jebał, / bo to mezalians byłby dla psa.“11

10 Najazd na poezję polska. [Überfall auf die polnische Poesie]. In: Kurier Poznański, 8.2.1923; vgl. OLAF BERGMAN (1998:217).

11 ,Vergeblich hast du eine Antwort erwartet. / Ich werde dir weder einen Nasenstüber noch einen Klaps geben. / Ich werde nicht einmal sagen, ein Hund soll dich mal vögeln, / Weil es für den Hund eine Mesalliance wäre.' In: Na pewnego endeka, co na mnie szczeka - fraszka [Ein Epigramm auf einen Nationaldemokraten, der mich anbellt], das er als Antwort auf antisemitische Presseattacken verfasste. Zit. nach Kultura - Poezja. Aufgezeichnet vom Internetradio PMB, 9.10.2009, 11:44 h 
Tuwim, ein leidenschaftlicher und zudem polyglotter Sammler von bibliophilen, kulturellen und linguistischen Kuriositäten, die bekanntlich neben kabarettistischen Texten zu seinen Favoriten gehörten, verfasste z.B. auch ein ,Polnisches Säuferlexikon`. ${ }^{12}$ Darin schrieb er im Vorwort, eine gewisse Kompetenz verratend:

Juszyński w poemacie satyrycznym ,Żydoswaros“ (1792) Żydom przypisywał specjalną fantazję w przezywaniu gorzałki, ale kilka zaledwie nazw wymnienił (,hardyban, gocha, gałda, sapsalicha, matutynka, stomachałka, parucha”), przy czym o tyle się pomylił, że nazwy te wcale nie są żydowskie. ${ }^{13}$

In dieses Lexikon, das in den Termini manche Überschneidungen mit der

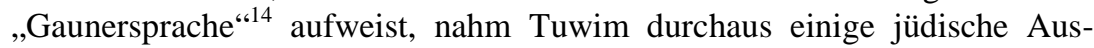
drücke auf, wie z.B. für: „wychlać, wypić, w gwarze złodziejskiej oznacza: aresztować“ ${ }^{15}$ Allerdings sagt Tuwim z. B. nicht, dass der Ausdruck „Bromfen“ (oder ,bronfen', ,Branntwein') aus dem Jiddischen kommt. Er führt nur „Na bromfen iść = na wódkẹ (, auf einen Schnaps gehen"), Warszawa“ an (Kapitel II. „Wódka w ogóle“:38). Bei dem folgenden Ausdruck weist er

12 Polski Stownik Pijacki i antologia bachiczna (1935), jetzt in einer illustrierten und ergänzten Neuausgabe (2000).

13 ,Juszyński sprach in dem satirischen Poem Żydoswaros (1792) den Juden einen besonderen Phantasiereichtum bei der Bezeichnung von Schnaps zu, hat aber lediglich einige Benennungen aufgeführt (,hardyban, gocha, galda, sapsaliche, matutynka, stomachalka, parucha"), bei denen er allerdings irrte, weil diese Bezeichnungen keineswegs jiddisch sind. ‘

14 Auch język błatny (,Blat-Sprache') genannt. In dieser Sprache gibt es auch Lieder, Gassenhauer, die oft aus jüdischer Feder stammten und, von jüdischen Interpreten in Polen und Russland gesungen, zu Volksliedern wurden - vgl. ULI HuFEN (2010). Bekannt ist, dass es in der polnischen wie in der deutschen ,Gaunersprache" viele jiddische Ausdrücke gibt, und diese zog auch Tuwim heran, etwa von Karol Estreicher (1903). Vgl. z. B. die Sammlung mit Abdrucken dreier alter Publikationen zum Thema der polnischen Gaunersprache von OlEXA HoRbATSCH (1979).

15 Tuwim (2000:20), Kapitel I. „Pić, wypić“. Tuwim zitiert aus URKe NaChaLNIK [d.i. Itzchak Baruch Farbarowicz] (1933:352). Poznań. Urke Nachalnik, 18971939, war ein bekannter polnisch-jüdischer Gangster und Schriftsteller zugleich, der im Alter von 22 Jahren Polnisch gelernt hat und sein Leben, von dem er über 15 Jahre im Gefängnis verbrachte, beschrieb. Er verfasste Gedichte, Kurzgeschichten und Theaterstücke. Am 11. November 1939 wurde er von den Deutschen erschossen. 
jedoch auf dessen jiddische Herkunft hin ${ }^{16}$ : „Ijasz, ijeś: z żydowskiego, złodziejskie“ (, aus dem Jiddischen, Diebesvokabular') oder „Chaim! Szulim!“, mit der Angabe „z hebrajskiego“ (,Leben, Friede, aus dem Hebräischen"), hier verballhornt (Kapitel IX. „Pogwarki i okrzyki pijackie“:124). Bei seinem Eintrag zu der Schenke als einem Verbrechertreffpunkt „szpize z żydowskiego: karczma złodziejska“ mit der Angabe: „Wiktor Ludwikowski i Henryk Walczak, ,Żargon mowy przestẹpców [...]', Warszawa 1923“, (d. h. ,aus der Sprache der Verbrecher', Kapitel XI. „Varia, dodatki, uzupełnienia“:144), ist Tuwim gleichfalls die jiddische Provenienz bekannt. Aber angesichts der Tatsache, dass die polnischen Juden in manchen Gegenden vielfach Schankwirte bzw. -pächter waren, ist die in diesem Lexikon aufgeführte kulturgeschichtliche wie sprachliche Ausbeute relativ gering, was wohl darauf zurückzuführen ist, dass diesbezügliche schriftliche Zeugnisse fehlten. ${ }^{17}$ Dort, wo es welche gab, hat Tuwim, der Bibliophile, sie angeführt, wie bei „Karczma - żydowska izba“ (,Schenke, eine jüdische Kammer") aus „,Wisła“, miesięcznik geograficzno-etnograficzny w Warszawie 1897, t. IX, s. 542“ (Kapitel XI. „Varia, dodatki, uzupełnienia“:144) oder „Bebłanina: ,Żyd ma z panem ugodę, że żadnemu poddanemu nie wolno będzie sobie kupić gdzie indziej innej wódki, jak tylko jego bebłaninę. ‘ Orędownik Naukowy“, czasopismo w Poznaniu, rok 1844, nr. 192“ (,Ein Gebräu: Der Jud” hat mit dem Edelmann eine Abmachung, dass keinem Untertanen erlaubt wird, einen anderen Wodka als sein Gebräu zu kaufen.‘; Kapitel II. „Wódka

16 Früher war die in Polen übliche Bezeichnung für Jiddisch ,,język żydowski“, die jüdische Sprache, und man sprach „,po żydowsku“ (, auf Jüdisch“, d.h. Jiddisch).

17 Bei Zenon Guldon (2005:12) heißt es, dass zwischen der Mitte des 17. und dem Anfang des 18. Jhd.s in manchen Gebieten Polens die Juden beinahe das Brau- und Schankmonopol besaßen, was für die Bevölkerung weniger schädlich war, als wenn dieses in den Händen der selbst dem Alkoholismus eher zugeneigten Fron-Bauern gelegen hätte: „Po zniszczeniach wojennych z połowy XVII i początku XVIII w. na niektórych terenach centralnej i wschodniej Rzeczypospolitej Żydzi odgrywali ważną rolę w gospodarce szlacheckiej Rzeczypospolitej, znacznie mniejszą zaś w Prusach Królewskich i zachodniej Wielkopolsce. W drugiej połowie XVIII w. na Mazowszu, Podlasiu i Podolu ponad połowa ojców rodzin żydowskich zajmowała się arendą karczem i browarów, niemal monopolizując tę działalność. Właściciele dóbr uważali, że znacznie gorsze rezultaty daje szynkowanie trunków przez chłopów pańszczyźnianych - nie należy , poddanych brać na szynk, raz że są niezdolni, po tym że dawany trunek przepijąc będzie‘. W Wielkopolsce karczmarze żydowscy stanowili zaledwie ok. 5\% ogółu osób zajmujących się wyszynkiem." Siehe auch GERSHON DAVID HUNDERT (2004). 
w ogóle“:50). Oder wenn er den polnisch-jüdischen Kulturhistoriker Samuel Adalberg (1868-1939) zitiert, der solche Ausdrücke wie den folgenden sammelte: „Pocałowal Mośka w brodẹ“ (,den Mojschek auf den Bart geküsst“; Kapitel V. „Stan i stopień nietrzeźwości“:70). ${ }^{18}$ Von der Gaunersprache zur Verbrechersprache ist es nur ein kleiner Schritt, und es verwundert kaum, dass die von einem jüdischen Pächter betriebene Schenke als Ort angeblicher jüdischer ,Verbrechen“ gegen die polnische Bevölkerung auch heute noch eine Rolle spielt: insbesondere nämlich auf den rabiaten, mit antijüdischen Ressentiments und antisemitischer Hetze erfüllten Seiten der entsprechenden polnischen Internetforen. Hier findet sich auch der berüchtigte Ausspruch von Kardinal Glemp bezüglich der angeblichen antipolnischen Aktivitäten jüdischer Schankwirte, die gezielt Alkohol an polnische Bauern ausgeschenkt hätten, um sie betrunken zu machen. ${ }^{19}$

Die Zeugnisse für Tuwims zumindest passive Kenntnis des Jiddischen sind durchaus glaubwürdig. So schrieb der sowjetische Schriftsteller Ilja Ehrenburg: „I have long heard of Sutzkevers poems. Both a wonderful Austrian novelist and the Polish poet Tuwim used to speak to me about them. ${ }^{\text {20 }}$ Auch DANIEL KAC (2004:42) berichtet, dass Tuwim Abraham Sutzkevers jiddische Gedichte kannte und schätzte:

Sutzkevers Gedichte erregten in den literarischen Kreisen Warschaus Interesse. Einmal, es war im Café „Ziemiańska“, wurde der Dichter aus Wilna Julian Tuwim vorgestellt und wurde von diesem gebeten, ihm eines seiner Gedichte

18 Vgl. Samuel Adalberg (1889-94), von dem auch der von Tuwim zitierte Trinkspruch: ,za zdrowie Kaczkosi, co Żydom wodę nosi“ (, auf die Gesundheit von Kaczkosia, die den Juden Wasser trägt') stammt (Kapitel IX. „Pogwarki i okrzyki pijackie“:126).

19 „...Treść eksponatów będzie dobrana według życzenia żydowskiego ruchu roszczeniowego i na pewno nie będą pokazane takie sprawy jak wyzysk i rozpijanie chłopów przez arendarzy i karczmarzy żydowskich, oraz wkład Żydów w prześladowanie Polaków w latach terroru Jakuba Bermana i w latach 1939-41, etc.“ Z.B. http://marucha.v3v.org/viewtopic.php?p=1656\&sid=cd0b21336b4f2b $382 f 35996089968389$ (9.6.2011); Iwo Cyprian Pogonowski: http://www. pogo nowski.com/display_pl.php?textid=442 (9.6.2011) oder hier:. http://stopsyjoniz mowi.wordpress.com/przedsiebiorstwo-holocaust/globalny-mit-holokaustu-iwocyprian-pogoowski/ (9.6.2011).

20 In: MAXIM SHRAYER (2007:535). Der hier genannte österreichische Romancier war Joseph Roth, den Sutzkever zufällig kennengelernt hatte und der darauf hinwirkte, dass Sutzkevers erste Lyriksammlung Lider 1937 durch den Warschauer jiddischen Pen Klub veröffentlicht wurde. 
vorzulesen. Nachdem Tuwim zugehört hatte, schwieg er eine längere Zeit und fragte dann: „Haben Sie noch sonst irgendwelche Gedichte?“ Sutzkever hatte einige dabei und las weitere, wobei Tuwim ihn aufforderte, „lesen Sie weiter“. Diese Szene ist selbstredend. Tuwim hat vom ersten Moment an den Wert von Sutzkevers Poesie erkannt. Roman Brandstaetter erzählte, dass, als er einmal in der „Ziemiańska“ mit Tuwim und dem gerade in Warschau weilenden Ehrenburg zusammensaß, dieser Tuwim fragte, ob in letzter Zeit ein für die polnische Poesie Bedeutsamer neu aufgekommen wäre. Tuwim antwortete - ja, aber nicht in Warschau, sondern in Wilna. Er heißt Abraham Sutzkever und schreibt auf Jiddisch. Damals war Sutzkever bereits Autor des berühmten Poems Cyprian Kamil Norwid und des Gedichts Feuervogel, welches als Ankündigung des späteren Poems Sibirien gilt. $^{21}$

Hätte Tuwim so wenig Ahnung vom Jiddischen gehabt, wie manche behaupten $^{22}$, hätte er sich natürlich niemals ein Urteil bilden, geschweige denn Begeisterung über Sutzkevers Poesie empfinden können. Er hätte auch in den so zahlreichen satirischen „Schmonzetten“ und Vaudeville-Texten, die er unter verschiedenen Pseudonymen verfasste und die in ihren angeblichen jüdischen Jargon-Darstellungen bis an die Grenze der antisemitischen Karikatur gingen, nicht so meisterhaft die Elemente des Jiddischen zum zugegebenermaßen - Zwecke der Komik in diese Texte eingebaut. ${ }^{23}$

21 „Wiersze Sutzkevera budziły zainteresowanie w warszawskim środowisku literackim. Pewnego razu, a było to w kawiarni ,Ziemiańska', twórca z Wilna został przedstawiony Julianowi Tuwimowi i poproszony przez niego o odczytanie jednego ze swoich wierszy. Po wysłuchaniu utworu Tuwim długo milczał, a potem zapytał: ,Czy ma pan przy sobie jeszcze jakieś wiersze?' Sutzkever miał ich kilka, czytał więc następne, a Tuwim nalegał: ,Niech pan czyta dalej." Ta scena mówiła sama za siebie. Tuwim od pierwszej chwili dostrzegł wartość poezji Sutzkevera. Roman Brandstaetter opowiadał, jak siedział kiedyś w ,Ziemiańskiej‘ z Tuwimem i bedącym w stolicy przejazdem Ehrenburgiem. Zapytał on Tuwima, czy pojawił siẹ ostatnio ktoś nowy, wartościowy w polskiej poezji. Ten odpowiedział - tak, nie w Warszawie jednak, lecz w Wilnie. Nazywa sie Abraham Sutzkever i pisze w języku jidysz. W tym czasie Sutzkever był już autorem słynnego utworu Cyprian Kamil Norwid i wiersza Ptak ognisty, stanowiącego zapowiedź późniejszego poematu Sybir.“

22 Z.B. AnNa AugustyniaK (2010): „[Siostra Juliana Tuwima] Urodziła się w sierpniu 1900 r. w mieszczańskiej rodzinie zasymilowanych Żydów. W domu mówiło się po polsku. Dzieci nie znały słowa w jidysz.“

23 Vgl. z. B. die ,Schmonzette ' Die Hochzeitsnacht, zit. in AleKSANDRA BudA (2010); auch KRZYSZTOF MASŁOŃ (2008). 


\section{Rajzel Żychlińska}

Die Dichterin Rajzel (oder auf Polnisch Rajzla) Żychlińska ${ }^{24}$, die, wie auch der kürzlich im Januar 2010 im Alter von 96 Jahren verstorbene Abraham (Avrom) Sutzkever, zu den bedeutendsten modernen jiddischen Schriftstellern zählt, ging hingegen literarisch einen anderen Weg - von der polnischen Sprache und Literatur hin zur jiddischen. Rajzel Żychlińska wurde 1910 in der Kleinstadt Gąbin in Masowien geboren, in der eine große jüdische Gemeinde lebte, die im Zweiten Weltkrieg vernichtet wurde. 1942 wurden das dortige Ghetto von den Deutschen aufgelöst und seine 3.030 Insassen (vgl. RÄKEL 2003) in die Vernichtungslager Chełmno oder Treblinka deportiert, darunter Rajzels Mutter, ihre Schwester Chane, ihre zwei Brüder und deren Kinder. Die Mutter stammte aus einer Rabbinerfamilie, der Vater war Gerber. Er emigrierte dreimal nach Amerika, wohin ihn zwei Töchter begleiteten, und starb 1928 in Chicago, während die Mutter mit den anderen Kindern, darunter Rajzel, in Polen zurückblieb. Rajzel besuchte von 1916 bis 1923 eine polnische Elementarschule, und da es in Gąbin kein Gymnasium gab, wurde sie von Privatlehrern unterrichtet. Mit 12 Jahren begann sie ein Tagebuch und Gedichte auf Polnisch zu schreiben. Erst fünf Jahre später schrieb sie ihr erstes Gedicht in Jiddisch. Die polnische Sprache war ihr seit der Kindheit vertraut (,meine Mutter sang mir ein polnisches Lied“, ZYCHLINSKI 2003:61) und die Natur in der polnischen Heimat, wie die Berge oder die Wälder, die sie nach dem Krieg evoziert, war ihr nahe: „Wie kühl, wie samtgrün / war das Moos im polnischen Wald, / wo ich unter Kiefernbäumen / in meiner Jugend träumte [...]“ (ZYCHLINSKI 2003:173). Von 1936 bis 1939 lebte sie als Bankangestellte in Warschau, wo sie als Autorin von nunmehr zwei Bänden mit avantgardistischen kurzen Gedichten in freien, ungereimten Versen Mitglied des jiddischen PEN war (Lider, 1936; Der regn singt, 1939) und bereits einen Ruf genoss. Nach dem Ausbruch des Krieges floh sie über den Fluss Bug nach Osten. 1941 heiratete sie den Mediziner Isaac Kanter aus Kolomea, mit dem sie im selben Jahr weiter nach Kasan flüchtete, wo 1943 ihr einziger Sohn Marek geboren wurde. Sie überlebten den Krieg, wofür sie

24 In Polen ist sie vor allem in katholischen Kreisen bekannt. Ins Polnische übersetzt wurden sieben ihrer Gedichte in die Anthologie jiddischer Dichtung von ZEW SZEPS (1980) aufgenommen sowie sechs in die Anthologie jiddischer Dichtung von ARNOLD SŁUCKI und SAlOMOn ŁaSTIK (1983). Auf Deutsch sind ihre Gedichte zuletzt in einer Gesamtausgabe erschienen: RAJZEL ZYCHLINSKI (2003). 
den Sowjets dankbar blieben, lebten bis 1944 im ukrainischen Mariupol, und kehrten 1947 nach Polen zurück. ${ }^{25}$ Die rückkehrenden Juden wurden in Niederschlesien, anders als polnische Heimkehrer, zunächst in einem Lager interniert, von dort ging es nach Łódź, wo die überlebenden Juden ein neues Zentrum der jiddischen Kultur aufzubauen versuchten. 1948 kam Żychlińskas dritter Gedichtband Tsu loytere bregn [Zu lichten Ufern] heraus, den sie ihren ermordeten Verwandten widmete und in dem sie die Hoffnung zum Ausdruck brachte, mit ihrer Familie fortan in ihrer Heimat in Ruhe und Frieden leben zu können. Aber das gelang ihr nicht mehr - zwar war sie eine von 251 überlebenden Gąbiner Juden, doch ihr Schtetl war ausradiert, und Polen war zum Friedhof ihrer Familie geworden, auf dem sie nicht mehr leben konnte. ${ }^{26}$ Sie dichtete noch: „Wir leben weiter auf der Erde, / die unser Blut und unsere Tränen getrunken hat [...] / Wir leben weiter, ein Häufchen, übriggeblieben fürs Kaddisch [...] Wir führn unsere Kinder an den kleinen Händen / vorbei an zerstörten Häusern, zerborstenen Wänden, / vorbei an toten Inseln toter Kinderjahre [...]“ (ZYCHLINSKI 2003:259). Aber in ihrem Fall gab es noch weitere Gründe, warum Polen nicht ihre Heimat bleiben

25 Die Angaben beruhen auf dem kurzen autobiographischen Text, den Żychlińska 1975 anlässlich der Verleihung des „Itzik Manger Preises für jiddische Literatur" verfasste; s. RAJZEL ZYCHLINSKI (1997:229-246), wiewohl sie wahrscheinlich schon 1946 zurückkam; ferner auf der Biographie Żychlińskas von KARINA VON TIPPELSKIRCH (2000) sowie HUBERT WiTTs (ZyChLINSKI 2003:892-916) Nachwort zu der Gesamtausgabe.

26 In dem Artikel Stosunki polsko-żydowskie w 30 lat po deklaracji soborowej Nostra Aetate [Die polnisch-jüdischen Beziehungen 30 Jahre nach der Konzilerklärung Nostra Aetate] beschreibt der polnische Erzbischof und Metropolit von Gniezno HENRYK MUSZYŃSKI (2000) in der katholischen Monatsschrift Znak bezüglich Zychlińskas Emigration als für Polen und Juden bedauerlich, dass im Bewusstsein der Nachkriegsgeneration der Juden Polen nunmehr als ein großer jüdischer Friedhof empfunden und nicht mehr als die geistige Heimat betrachtet wird: „Skutkiem tego wszystkiego Polska w świadomości powojennych pokoleń Żydów nie jest już odczuwana jako duchowa ojczyzna współczesnej społeczności żydowskiej, lecz postrzegana raczej jako jej mogiła, jako jeden ogromny cmentarz. Fakt ten ma zgubne konsekwencje dla obu stron zarówno dla Żydów, jak i Polaków. Jeśli chodzi o stronę żydowską, to urodzona w roku 1910 w polskim Gąbinie poetka Rajzel Żychlińska - która przeżyła zagładę i powróciła do Polski, aby jednak już w roku 1948 opuścić ją ponownie i wyjechać do Nowego Jorku - wyraziła to, co myślało z pewnością wielu, którzy podobnie jak ona wkrótce po wojnie odwrócili się od Polski, gdy powiedziała, ,że nie może żyć na cmentarzu', a tym bardziej na cmentarzu, który przez wydarzenia pierwszych lat powojennych został ponadto zbezczeszczony.“ 
konnte. Der Antisemitismus der polnischen Bevölkerung war nämlich auch nach dem Krieg virulent, und die sowjetischen Repressalien gegen jüdische Intellektuelle trugen zu einem Klima bei, das zahlreiche jiddische Dichter, darunter auch Sutzkever, veranlasste, das Land endgültig zu verlassen. Als außerdem Rajzels Mann, Isaac Kanter, 1948 in einem Brief aus Lodz, den er in New York veröffentlichte, die Kulturpolitik der jüdischen kommunistischen Funktionäre kritisierte, hatte sich das Ehepaar politisch und sozial ins Abseits manövriert und reiste zunächst nach Frankreich aus. 1951 konnten sie in die USA emigrieren, wo Żychlińska u. a. an der New School for Social Research studierte und ihre poetische Arbeit auf Jiddisch fortsetzte. Doch die Traumata verließen sie wie die meisten anderen Überlebenden nicht mehr. Verfolgt von Ängsten, dem an Agoraphobie leidenden Tuwim ähnlich, wechselte sie zuletzt mehrfach ihren Wohnsitz, so floh sie z.B. 1989 nach dem Erdbeben in San Francisco nach New York zurück, um schließlich 2001 in einem Pflegeheim im kalifornischen Walnut Creek zu sterben. Es verbanden Rajzel Żychlińska und Sutzkever nicht nur das osteuropäisch-jüdische Schicksal und die lebenslange Trauer, sondern auch die gemeinsamen polnischen geographisch-kulturellen Wurzeln, die sich in ihrer beider poetischen Sprache widerspiegelten.

\section{Abraham Sutzkever}

Wie Tuwim die polnische, so hat auch Sutzkever die jiddische Literatursprache auf eine vorher unerreichte Höhe gehoben und sie durch vielfältige Neuschöpfungen bereichert (VALENCIA 2009:19). Sutzkever wurde 1913 als Nachfahre einer gelehrten Rabbiner-Familie in Smorgon, südöstlich von Wilna, damals zum Russischen Reich gehörend, geboren und besuchte in seiner Kindheit den Cheder [jüdische religiöse Elementarschule]. 1915, während des Ersten Weltkriegs, flüchtete die Familie nach Omsk in Sibirien, wo der herzkranke Vater im Alter von 30 Jahren starb. Sutzkever verklärte in seiner Poesie stets die Kindheit in Sibirien, das die Familie 1920 nach dem Tod des Vaters wieder verließ, um nach Litauen zurückzukehren. Da die Wohnung in Smorgon zerstört war, zog die Mutter mit den drei Kindern nach Wilna, nunmehr polnisches Territorium, wo sie von einem Onkel aus Amerika unterstützt wurde. Die reiche religiöse und später auch weltliche jüdische Kultur Wilnas, die blühende jiddischsprachige Literatur und Wissenschaft, bescherten der Stadt den Ruf, ,Yerusholayim de Lite“ (,Jerusalem Litauens“) $\mathrm{zu}$ sein, aber Sutzkevers frühe Erziehung war eher polnisch als jiddisch 
geprägt, denn er besuchte ein polnisches Gymnasium, an dem er die polnische Literatur kennen und lieben gelernt hat. Die Stadt Wilna war damals sowohl ,jüdisch“ als auch „polnisch“, wie Czesław Miłosz, der berühmte polnische Sohn der Stadt, feststellte („Vorwort“ zu KAC 2004:7). Dem Gymnasiasten Sutzkever haben es besonders die polnischen Klassiker der Romantik angetan, allen voran sein litauischer Landsmann Adam Mickiewicz, Juliusz Słowacki, dessen Vater Literaturprofessor an der Wilnaer Universität war, und Cyprian Kamil Norwid (1821-1883). Von den Zeitgenossen inspirierten ihn Bolesław Leśmian und Julian Tuwim am meisten. Norwid, einem der wichtigsten, ins Pariser Exil geflüchteten polnischen romantischen Dichter und Freund Chopins, der von der Bewegung Młoda Polska (,Junges Polen') wiederentdeckt worden war, hatte Sutzkever, der auch an der Wilnaer Universität als Gasthörer Literatur studierte, später auf Jiddisch ein Poem, Cyprian Norwid ${ }^{27}$, gewidmet. Dieses Poem, pathetisch zwar, war doch, wie etliche Werke Sutzkevers, zugleich schon visionär, ähnlich jenen Tuwims, die eine erneute, baldige ,Verknechtung' Polens voraussahen. Sicherlich hat die Atmosphäre jener Jahre damit zu tun, dass nach dem Tod des polnischen Premierministers Marschall Józef Piłsudski, dem die Rechte eine zu freundliche Haltung den Juden gegenüber vorwarf, diese Rechte ihre judenfeindliche Politik nun ungehindert an den Tag legen konnte. Hinzu kam, dass Piłsudski ein Jahr vor seinem Tod, 1934, mit dem Deutschen Reich einen auf zehn Jahre befristeten deutsch-polnischen Nichtangriffspakt schloss, was den Antisemitismus weiter verstärkte. Der junge Sutzkever bewunderte den großen Patriotismus des Dichters Norwid und identifiziert sich mit ihm:

Und du liebst dein Volk, das in

Knechtschaft gezwungen liegt

$[\ldots]$

und du liebst die polnische, die traurige Erde.

In jeder krummen kleinen Hütte siehst du große Schönheit

[...]

Vergittert liegt dein Vaterland.

Es fiebert der Pole

und rohe Fäuste erheben sich gegen die Moskalen.

Du sitzest in einer Pariser Schenke fantasierend beim Cognac

und schreibst auf schmale Blättchen zu Klängen der Zimbeln

$[\ldots]$

$27 \quad 1936$ entstanden, 1937 in seiner ersten Gedichtsammlung lider veröffentlicht. 
Es muß ein Licht da sein, das alle Menschen fühlen sollten, sehen - eine Liebe, die Schönheit und eine Schönheit, die Liebe ist. Nur dann wird eine Bruderschaft sein, wie es sie noch nie gegeben hat [...] Ich liebe mein Volk, wie jeder liebt

[...]

Dein Blut wird ewig fiebern, wie auf dem Tischrand dein soeben geschriebenes Lied, dein Fortepian Szopena. ${ }^{28}$

Dass Tuwim in Sutzkevers jiddischen Gedichten eine verwandte Seele entdeckte, verwundert kaum, denn Tuwim selbst schrieb ja in „Wir, die polnischen Juden“, warum er sich als Pole fühlte, nicht zuletzt, weil ihm ,die Birke und die Weide näher als die Palme und Zypresse sowie Mickiewicz und Chopin teurer denn Shakespeare und Beethoven wären“" (TUWIM 1984:28). Auch Sutzkevers jung verstorbene Schwester Etel, die von der Mutter unterrichtet wurde, deklamierte im Alter von 13 Jahren auswendig Gedichte der polnischen Nationaldichter Juliusz Słowacki und Adam Mickiewicz (KAC 2004:24), was in damaligen jüdischen Kreisen keineswegs selbstverständlich war. In die Kenntnisse der klassischen und modernen jiddischen Literatur wurde Sutzkever erst im Alter von 15 Jahren durch Freunde, vor allem aber durch seine spätere Frau Frejdke Levitan ,eingeweiht', die schon mit 14 Jahren in der bibliographischen Abteilung des YIVO arbeitete (VALENCIA 2009:29), und er selbst verbrachte viel Zeit in der damals größten jiddischen Büchersammlung Europas von 40.000 Bänden, der StrashunBibliothek, wo er an seinen Jiddisch-Kenntnissen feilte. Seine Liebe zur Literatur umfasste neben den polnischen auch deutsche und französische Autoren, was ihn ebenfalls mit Tuwim verband, und wie jener huldigte Sutzkever dem Modernismus, seine Dichtung war neu- und andersartig.

Doch während die jiddischen Dichter die kulturellen Einflüsse der Umgebung in sich aufsogen, sich zunehmend polnisch fühlten, blieb ihre Kultur den christlichen Nachbarn meist unbekannt bis fremd, auch wenn sie in der jüdischen Welt ein breites Echo fand wie etwa die Wilnaer Künstler- und Dichter-Gruppe „Yung Vilne“, die von 1927 bis1943 existierte und zu der neben dem distanzierten Außenseiter Sutzkever auch die bekannten jiddischen Autoren Chaim Grade und Schmerke Katscherginski gehörten. Sutzkever war es gelungen, mit seiner Frau aus dem Wilnaer Ghetto zu fliehen, nachdem sein neugeborener Sohn dort getötet und seine Mutter erschossen

28 Abraham SutZKeVer (1963:68-74). Es handelt sich um das gleichnamige, Chopin gewidmete Gedicht Norwids. Übersetzung E. G. 
worden war. Sie schlossen sich in den Wäldern den Partisanen an, von wo sie ein von seinem Mentor und Vorkriegsbewunderer Ilja Ehrenburg aus Moskau geschicktes Flugzeug herausholte. Aus Moskau kehrte Sutzkever nach Polen zurück, doch kurz nachdem Tuwim zurückgekommen war, verließ Sutzkever das Land und begab sich mit einem ihm von Golda Meir beschafften falschen Pass nach Eretz Israel, damals in der Endphase als britisches Mandatsterritorium, wo er fortan lebte und die legendäre jiddische Zeitschrift Di goldene keyt [Die goldene Kette] herausgab. Sein Schreiben war vor allem dem Gedenken an die Toten gewidmet und sein Wirken der Bewahrung der jiddischen Sprache. Als polnischer Dichter wird er in seiner Heimat bisher nicht wahrgenommen.

\section{Arnold Słucki}

Nach Israel kam, wenn auch unfreiwillig und sehr viel später, nämlich 1968, auch der letzte der hier skizzierten polnischen Dichter, Arnold Słucki (vgl. GRÖZINGER 1986). Er gehört zwar nicht mehr zu den Autoren der Zwischenkriegszeit, steht aber sowohl durch sein polnischsprachiges Werk wie durch seine bewusste Heimholung jiddischer Dichter der hier genannten Gruppe nahe und hat eine wichtige Mittlerfunktion zwischen der polnischsprachigen und jiddischsprachigen Literatur inne. Auch ihm diente Tuwim als Vorbild, was sich nicht zuletzt in seiner Literatur für Kinder zeigt. Und wie dies TUWIM (1950) zuvor in seinem Poem Kwiaty polskie [Polnische Blumen] so deutlich zum Ausdruck gebrachte hatte, litt Słucki auch im Ausland zunächst in Israel, dann in Deutschland - unheilbar am Heimweh nach Polen (dazu GRÖZINGER 2005). Der 1920 in Tyszowce Geborene und traditionell jüdisch Erzogene gehörte zwar einer späteren Generation an, die erst nach dem Zweiten Weltkrieg publizistisch in Erscheinung trat, doch auch er entging nicht dem Schicksal der polnischen Juden, ob in den Wirren des Krieges, den er in der Sowjetunion überlebte, oder des polnischen staatlichen Antisemitismus, dem er 1968 zum Opfer fiel. Lange in Polen verschwiegen, wurde er erst in den Jahren nach der Wende wiederentdeckt.

Als Kommunist huldigte Słucki zunächst dem Sozialistischen Realismus, doch wegen seiner bald zutage tretenden Unangepasstheit, seinem Unwillen, sich der „Enge des ideologischen und Denkhorizonts“ und dem „Infantilismus“ (SŁUCKI 1957:136) zu beugen, wurde er, der sich nun dem Surrealis- 
mus zuwandte ${ }^{29}$, für das Regime zur Persona non grata, und man stieß ihn als Juden nun wie einen Fremdkörper ab, was Słucki nie mehr verwunden hat. In seiner Nach-Tauwetter-Lyrik ab den späten 1950er Jahren neigte Słucki zunehmend dem Metaphysischen zu und der Trauer und Nostalgie nach der vernichteten und verlorenen Welt seiner Kindheit - dem Schtetl, das er „Chagallewo“ ${ }^{\star 30}$ nannte. Der nun vom Geist des neuen Polen Enttäuschte besann sich auf die jüdischen und jiddischen Quellen seiner Herkunft, die er z.B. in dem Gedicht Die Gene auf seine ihm besondere Weise heraufbeschwört: „Auch ich sage: / Gene. / Es gibt noch Gene, mitgebracht / aus Gehenna, / Auf A - wie Adam / auf E - wie Eva - / aus dem Paradies, / aus den galizischen Abenteuern meines Großvaters [...]. ${ }^{\text {‘31 }}$ Norwid und Tuwim ähnlich, wurden Słuckis heimatlicher Fluss, die Huczwa, sowie die Weichsel zu Chiffren seiner Poesie, besonders nach der erzwungenen Emigration nach Israel, wo er sich trotz seiner Hebräischkenntnisse entwurzelt fühlte und seiner schwachen Gesundheit wegen nicht leben konnte. In der israelischen Hafenstadt Aschdod dichtete der Entwurzelte im April 1969: „Wie lebendig, es wehte hier der Warschauer Frühling; er bläst aus der gelben Ödnis - und auf dem Eukalyptus ein Vogel - [...]" (Gedicht Ein Konzert; SŁUCKI 1982a:245). Als Galizianer war Słucki, wie so viele der ehemaligen K.-u.-K.Bürger, auch der deutschen Sprache mächtig. ${ }^{32}$ Und um dem verlorenen polnischen Arkadien näher zu sein, reiste Słucki 1970 nach Deutschland weiter. Doch fand er hier wie in Israel nur die schmerzliche Fremde vor. Słucki starb, erst 52-jährig, 1972 in Berlin, wo er in einem staatlich finanzierten Ehrengrab ruht.

Elf Jahre nach seinem Tod erschien in Polen die ,Anthologie der jüdischen Poesie', die Słuckis Verbundenheit mit der Literatur und Kultur der Juden in Polen auf beeindruckende Weise nachweist (SŁUCKI 1983). Der polnische

29 ARNOld SŁUCKI (1982:14) - hier zitiert Anna Kamieńska Słuckis Artikel in Wspótczesność von 1965.

30 Das Poem Szagalewo hat Słucki Adolf Rudnicki gewidmet. Aus dem Band Dzwony nad Wista [Glocken an der Weichsel] von 1958, zit. nach SŁUCKI (1982:35-39).

31 Geny aus dem Band Dolina Dziwów [Das Tal der Wunder]; SŁUCKI (1964:10). Meine Übersetzung, ebenso wie die in diesem Abschnitt folgenden Übersetzungen von Słuckis Gedichten.

32 Zum Thema der Wechselbeziehungen zwischen der jüdischen, der slawischen und der deutschen Kultur hat vor allem MARIA KŁAŃSKA (1994, 1999) Grundlegendes geschrieben. 
Dichter hat in den Jahren 1958-1965 das monumentale Unterfangen der Anthologie in die Wege geleitet, das sich an der von Samuel Hirschhorn (1876-1942) im Jahre 1921 herausgegebenen Antologia poezji żydowskiej, in der es allerdings auch Übersetzungen aus dem Hebräischen gab, orientiert. Hirschhorns, wie auch Słuckis, Anliegen war es gewesen, in der Tradition der Aufklärer jüdische Kultur im polnischen Kontext darzustellen, denn „Polen war die Wiege der modernen jiddischen Poesie“, wie Słucki in seiner Einleitung, die eine große Kennerschaft verrät, betont (SŁUCKI 1983:7). Und er verdeutlicht: „Die Entwicklung der jiddischen Poesie in Polen in den zwanzig Jahren zwischen den Kriegen zeichnet ein gewisser Synkretismus in der Art der Adaptierung der europäischen und der polnischen Poesie aus." (SŁUCKI 1983:13) Słucki weist den polnischen Leser auch auf den atemberaubenden Reichtum und die Vielseitigkeit dieser Dichter und ihrer Poesie hin, die vor unterschiedlichen Hintergründen entstand und in der Literaturgeschichte ohne Parallele sei, und er bedauert, dass in das umfangreiche Buch von 554 Seiten viele weitere Dichter nicht aufgenommen werden konnten. Die Anthologie umfasst die Werke von 103 Autoren, die von 59 polnischen zeitgenössischen Dichtern, Juden und Nichtjuden, angefangen von Jerzy Ficowski über Anna Kamieńska, Tymoteusz Karpowicz, Wisława Szymborska bis hin zu Jarosław Iwaszkiewicz, übersetzt beziehungsweise nachgedichtet wurden. Słucki betrachtete diese mit kurzen biographischen Angaben ausgestattete Anthologie, für die er selbst 61 Gedichte - darunter die meisten von Abraham Sutzkever - übersetzte, nur als einen ersten Schritt. Doch als sie 1968 zum Druck gehen sollte, kam das Ende für Słucki, wie für viele seiner Kollegen und den Rest des polnischen Judentums. ${ }^{33}$ Die kulturelle und menschliche Leere, die danach folgte, ist bis heute in der polnischen Gesellschaft und Kultur spürbar, die Narben sind, trotz der Bemühungen Einzelner, nicht verheilt. Der polnische Dichter Słucki fühlte sich ,amputiert“, wie es in dem Gedicht Amputacja aus dem Zyklus ,Requiem für einen Esel“ heißt: „Und es tut immer noch weh wie ein amputiertes Bein / diese

33 Bekanntlich gab es nach den sogenannten ,März-Unruhen“ des Jahres 1968, für die die kommunistischen Behörden ,Zionisten“ verantwortlich machten, eine staatlich angeordnete antisemitische Hetze. Die meisten der nach der Emigrationswelle der Jahre 1956/57 noch in Polen verbliebenen Juden, etwa 25.000, wurden zum Verlassen des Landes genötigt; diejenigen, die Mitglieder der Partei waren, wurden ausgeschlossen; die Juden mussten ihre Arbeitsplätze verlassen, während ihre Kinder aus den Universitäten entfernt wurden. Nach dieser Emigrationswelle blieb in Polen nur eine quantité negligéable von einigen wenigen Tausend jüdischen Einwohnern. 
gefiederte Leere und die Asche, die uns juckt, / angeblich hat man in Masowien zwei Weiden gesehen / in grünen Talessim und irgendeine Marktbude / in der Mitte des Himmels [...].“ (SŁUCKi 1982a:158) ${ }^{34}$ So erging es auch den anderen Emigranten, als sich die Träume von einer polnisch-jüdischen Symbiose in nichts auflösten. Um mit Słuckis Worten aus dem Gedicht ,Die Einschläferung des Engels' aus dem Band „Biographie eines Engels' abzuschließen: „Sie schläferten ihn ein / und schnitten ihm einen Flügel ab, / weckten ihn / und schnitten ihm den zweiten ab, / fliegen konnte er nicht mehr, / aber die Sprache ist ihm geblieben [...].“ (SŁUCKI 1982a:27) Es war die polnische Sprache.

\section{Literatur}

ADAlBERG, SAMUEL (1889-94): Księga przystów, przypowieści i wyrażeń przystowiowych polskich. [Das Buch der polnischen Sprichwörter, Redensarten und Ausdrücke]. Warszawa.

AUgustyniaK, ANNA (2010): Irena płaczaca za szafa. [Irena, hinter dem Schrank weinend]. In: Wysokie Obcasy: http://www.wysokieobcasy.pl/wysokie-obcasy/1,5366 2,8682993,Irena_płaczaca_za_szafą.html (23.11.2010).

BeRgMAn, OlaF (1998): Narodowa Demokracja wobec problematyki żydowskiej w latach 1918-1929. [Die Nationaldemokratie und die jüdische Frage in den Jahren 1918-1929]. Poznań.

Buda, AleKSAndRa (2010): Język szmoncesu. [Die Sprache der Schmonzette]. In: Stacja Kultura.pl: http://stacjakultura.pl/2,10,5919,Jezyk_szmoncesu,artykul.html (12.2.2010, aktualisiert am 12.7.2010).

CoHEn, NATHAN (2003): Books, Writers and Newspapers. The Jewish Cultural Center in Warsaw, 1918-1942 (Hebräisch). Jerusalem.

ESTREICHER, KAROL (1903): Szwargot więzienny. [Gefängnisgeschwätz]. Kraków.

Fuks, MARIAN (1979): Prasa żydowska w Warszawie 1828-1939. [Jüdische Presse in Warschau 1828-1939]. Warszawa.

- (2002): Żydowska literatura. [Jüdische Literatur.] In: BACHÓRZ, JóZEF / KowALCZYKOWA, ALINA (eds.) Stownik literatury polskiej XIX wieku. Wrocław.

GRÖZINGER, ElVIRA (1983): Julian Tuwim - ein polnischer Dichter. In: Exil 1:31-41.

- (1986): Das verlorene Paradies: Zu Arnold Stuckis Dichtung. In: GRÖZINGER, ElVIRA / LAWATY, ANDREAS (eds.): Suche die Meinung. Karl Dedecius dem Übersetzer und Mittler zum 65. Geburtstag. Wiesbaden.

34 ,Talessim‘ (Jiddisch) sind die Gebetsmäntel der Juden. 
- (1989): Julian Tuwim. In: Arnold, Heinz Ludwig / Domsch, Sebastian (eds.): Kritisches Lexikon zur fremdsprachigen Gegenwartsliteratur (KLfG). Bd. 10. München.

- (1991): Ein Dreiecksverhältnis in Geschichte und Gegenwart. Polen, Deutsche, Juden. In: Deutsch-polnische Ansichten zur Literatur und Kultur. Jahrbuch des Deutschen Polen-Instituts 1990:84-108.

- (1991): Die Literatur Polens. In: Arnold, Heinz Ludwig / Domsch, Sebastian (eds.): Kritisches Lexikon zur fremdsprachigen Gegenwartsliteratur (KLfG). Bd. 12. München.

- (1999): Das „Judenkind” und „schreckliche Bürger“. Ein Panoptikum der Zwischenkriegsjahre in Julian Tuwims Lyrik. In: KostA, PETER et al. (eds.): Juden und Judentum in Literatur und Film des slavischen Sprachraums. Die geniale Epoche. Wiesbaden, 155-172.

- (1999): Juden und das Judenbild in der polnischen Literatur von 1918 bis 1989. In: BlachetTA-MadajCZyK, Petra (ed.): Lebn wil ich - was blieb: jüdische Friedhöfe in Polen. Darmstadt, 145-153.

- (2000): Juden und das Judenbild in der polnischen Literatur von 1918 bis 1989. In: Blachetta-Madajczyk, Petra (ed.): „Lebn wil ich”. To co pozostało. Cmentarze żdowskie w Polsce. Białystok, 131-150.

- (2001): ,Trójkąt‘ polsko-niemiecko-żydowski jako temat polskiej literatury wspótczesnej. [Das polnisch-deutsch-jüdische ,Dreiecksverhältnis“ als Thema der polnischen Gegenwartsliteratur]. In: ChrZĄSTOWSKA, BożENA (ed.): Obcowanie z wolnością. Poznań/Berlin, 177-190.

- (2005): ,Polin - Du bist wie die Gesundheit... ‘. Die polnischen Juden und das Exil. In: GelHARD, DoROtheE (ed.): In und mit der Fremde. Über Identität und Diaspora im Ostjudentum. Frankfurt (M.) u. a., 13-33.

Guldon, ZENON (2005): Z przeszłości Żydów polskich. [Aus der Vergangenheit der polnischen Juden]. Kraków.

Hertz, Aleksander (1988): The Jews in Polish Culture. Translated by Richard Lourie. With a Foreword by Czesław Miłosz. Ed. Lucjan Dobroszycki. Evanston/Il.

Horbatsch, OleXa (ed.) (1979): Polnische Gaunersprache I \& II. Frankfurt (M.).

Hufen, Uli (2010): Das Regime und die Dandys. Russische Gaunerchansons von Lenin bis Putin. Berlin.

Hundert, Gershon DAVID (2004): Jews in Poland-Lithuania in the Eighteenth Century: A Genealogy of Modernity. Berkeley.

KAC, DANIEL (2004): Wilno Jerozolima byto. Rzecz o Abrahamie Sutzkeverze. [Wilna war Jerusalem. Über Abraham Sutzkever]. Z przedmową Czesława Miłosza, i wyborem dzieł Sejny Sutzkevera. Sejny.

KŁAŃSKA, MARIA (1994): Aus dem Schtetl in die Welt, 1772 bis 1938. Ostjüdische Autobiographien in deutscher Sprache. Wien/Köln/Weimar.

- (1999): Problemfeld Galizien. In deutschsprachiger Prosa 1846-1914. Wien/Köln/ Weimar. 
Lec, Stanislaw Jerzy (1986): Steckbriefe. Epigramme, Prosa, Gedichte. Hrsg. und übertragen von Karl Dedecius. München.

MACiĄG, WŁodzimierz (ed.) (1981): Mały Stownik Pisarzy Polskich. [Kleines Lexikon polnischer Schriftsteller]. Warszawa.

MasŁoń, Krzysztof (2008): Mistyka finansów. [Die Mystik der Finanzen]. In: Rzeczpospolita: http://www.rp.pl/artykul/178308.html?print=tak (18.8.2008).

MusZyŃSKI, HENRYK (2000): Stosunki polsko-żydowskie w 30 lat po deklaracji soborowej Nostra Aetate. [Die polnisch-jüdischen Beziehungen 30 Jahre nach der Konzilserklärung Nostra Aetate]. In: Znak 541.

NACHALNIK, URKE (1933): Życiorys własny przestępcy. [Lebenslauf eines Verbrechers]. Poznań.

ProkoP-JANIEC, EUGENIA (1992): Międzywojenna literatura polsko-żydowska jako zjawisko kulturowe $i$ artystyczne. [Die polnisch-jüdische Literatur der Zwischenkriegszeit als ein kulturelles und künstlerisches Phänomen]. Kraków.

- (1996): Międzywojenna poezja polsko-żydowska. Antologia. [Die polnisch-jüdische Dichtung der Zwischenkriegszeit. Eine Anthologie]. Kraków.

RÄKEL, HANS-HERBERT (2003): Ein Fenster flammt auf. Die Gesamtausgabe der Gedichte von Rajzel Zychlinski. In: Süddeutsche Zeitung, 21.7.2003.

SANDAUER, ARTUR (1982): O sytuacji pisarza polskiego pochodzenia żydowskiego $w$ $X X$ wieku (Rzecz, która nie ja powinienem byt napisać...). [Über die Lage eines polnischen Schriftstellers jüdischer Abstammung im 20. Jahrhundert. (Eine Sache, die nicht ich hätte schreiben sollen...)]. Warszawa.

Scheps, Samuel (1989): Polish Literature in Hebrew Attire. Polish and Jewish Writers in the Mirror of Selected Translations of Their Works (Hebräisch). Edited and preceded with an Introduction by Asher Wilcher. Jerusalem.

SCHMID, HeRTA (1998): Sprachursprungstheorien bei Bolestaw Leśmian und Bruno Schulz. In: GRÖZINGER, KARL E. (ed.): Sprache und Identität im Judentum. Wiesbaden.

Shrayer, MaXim (ed.) (2007): An Anthology of Jewish-Russian Literature. Vol. 1: 1801-1953. Two Centuries of Dual Identity in Prose and Poetry. New York.

SŁonimski, ANTONi (ed.) (1946): Literatura na emigracji. Antologia „Nowej Polski“. [Literatur in der Emigration. Eine Anthologie des „Neuen Polen“]. Łódź.

SŁUCKI, ARNOLD (1957): Polemiki i refleksje. [Polemiken und Reflexionen]. Warszawa. - (1964): Dolina Dziwów. [Das Tal der Wunder]. Warszawa.

- (1982): Poezje wybrane. [Ausgewählte Dichtungen]. Wyboru dokonała, wstẹpem i notą opatrzyła Anna Kamieńska. Warszawa.

- (1982a): Biografia Anioła. [Biographie eines Engels]. Wstępem poprzedził Ryszard Matuszewski. Warszawa.

- (ed.) (1983): Antologia poezji żydowskiej. [Anthologie der jüdischen Poesie]. Wybór oraz noty i przypisy Salomon Łastik, redakcja i słowo wstẹpne A.S. Warszawa. 
STĘPIEŃ, MARIAN (1989): Dalekie drogi literatury polskiej (szkice o polskiej literaturze emigracyjnej). [Die weiten Pfade der polnischen Literatur. (Skizzen über die polnische Literatur der Emigration)]. Kraków.

Sutzkever, Abraham (1963): Poetishe verk. [Poetische Werke]. Bd. I: lider un poemes fun di yorn 1934-1947. [Lieder und Dichtungen aus den Jahren 1934-1947]. Tel Aviv (Jubiläumsausgabe).

SzEPS, Zew (ed.) (1980): Antologia Poezji Żydowskiej (1868-1968). [Anthologie jüdischer Dichtung (1868-1968)]. Wybór, przekład i opracowanie. Londyn.

TIPPELSKIRCH, KARINA VON (2000): „Also das Alphabet vergessen?“ Die jiddische Dichterin Rajzel Zychlinski. Marburg.

Tuwim, Julian (1950): Kwiaty polskie. [Polnische Blumen]. Kraków.

- (1963): Cicer cum Caule czyli Groch z kapusta. Panopticum i Archiwum Kultury Seria III. [Cicer cum Caule oder Kraut mit Rüben. Panoptikum und Kulturarchiv 3. Folge]. Do druku przygotował i posłowem opatrzył Józef Hurwic. Warszawa.

- (1964): Dzieła Tom V, Pisma Proza. [Werke Band V, Prosaschriften]. Opracował Janusz Stradecki. Warszawa.

- (1984): My, Żydzi Polscy, We Polish Jews.... Wydał / Editor Ch. Shmeruk. Jerusalem. - (1990): Pisma Zebrane. Juwenilia 2. [Gesammelte Schriften. Juvenilien 2]. Opracowali Tadeusz Januszewski i Alicja Bałakier. Warszawa.

- (2000): Polski Stownik Pijacki. [Polnisches Säuferlexikon]. Wstępem zaprawił Jerzy Pilch, suplementem doprawił Piotr Bikont. Warszawa.

VALENCIA, HEATHER (2009): Einleitung. In: SuTZKEVER, ABRAHAM: Geh über Wörter wie über ein Minenfeld. Lyrik und Prosa. Auswahl, Übersetzung und Anmerkungen von Peter Comans. Frankfurt (M.)/New York.

- ZyChlinski, RaJZel (1997): Gottes blinde Augen. Ausgewählte Gedichte. Aus dem Jiddischen von Karina Kranhold. Hrsg. von Karina Kranhold und Siegfried Heinrichs. Chemnitz.

- (2003): di lider 1928-1991. Die Gedichte. Jiddisch und Deutsch. Hrsg. und übertragen von Hubert Witt. Frankfurt (M.). 